\title{
The Validation of a Quantitative Measure of Self-authorship among Chinese University Students
}

\section{Dorothy Tao Li}

The University of Hong Kong, Hong Kong.

\begin{abstract}
This paper presents the preliminary evidence for validating the Selfauthorship Section of the Career Decision Making Survey (SA-CDMS; Creamer, Baxter Magolda, \& Yue, 2010) among Chinese university students. Two samples of undergraduate students (Stage One, N=263; Stage Two, N= 663) from three universities in the People's Republic of China participated in this study. In the first stage, the SA-CDMS was translated from English to Chinese, with the psychometric properties preliminarily examined by exploratory factor analysis and internal consistency test. The original 18 -item SA-CDMS model failed to identify the theoretical structures as expected, however, several modifications could be identified from the results of Stage One. In the second stage, the modified SA-CDMS showed acceptable reliability and validity based on the results of confirmatory factor analysis and Cronbach's alpha coefficients. In addition, Pearson's correlation analysis was employed by Stage Two to examine the correlations among the demographic factors, three phases, and three dimensions of self-authorship framework. In general, the current study provided evidence for utilizing SACDMS in the Chinese higher education context. This study added to the literature of the research on self-authorship and offered practical implications to educators and policymakers in promoting self-authorship development among Chinese university students.
\end{abstract}

Keywords: Self-authorship; quantitative measure; higher education. 


\section{Introduction}

Self-authorship, defined as "the internal capacity to define one's own beliefs, identity, and relationships" (Kegan, 1994; p.11), is considered as one of the key developmental capacities of university students in achieving a variety of university outcomes (Baxter Magolda, 2009). Little has been known for self-authorship development among Chinese university students (Zhang \& Cen, 2017). Besides, the qualitative design was the dominant research methodology adopted by the existing research (Perez, 2017). Pizzolato (2007) argued that developing and utilizing a quantitative measure to assess self-authorship was important because it could provide insights into the subtle nuances that happened in/across stages of self-authorship development. Employed a two-stage design, the current study aimed at validating a quantitative measure, the Self-authorship Section of the Career Decision Making Survey (SA-CDMS; Creamer, Baxter Magolda, \& Yue, 2010), among Chinese university students. To deepen the understanding of the theoretical structure of SACDMS, Stage Two of the current study also examined the correlations among the demographic factors, the three theoretical dimensions, and the first three phases in the development of self-authorship. Conducting such research is theoretically significant because it would enrich the literature by producing empirical evidence for validating SACDMS in the context of Chinese higher education. The current study is also significant on the practical level because it would have implications for the educators, administrators, and policymakers who are willing to enrich the knowledge of self-authorship and promote its development among Chinese university students. The remainder of this paper presents the related works, research methods, and results, respectively. Limitation, discussion, and conclusion are written at the end.

\section{Related works}

The conceptualization of self-authorship was based on Kegan's (1994) theory of Selfevolution that followed Piaget's (1950) constructivist-developmental tradition. The dimensions of self-authorship were related to three questions in the meaning-making process, including "How do I know?" (epistemological), "Who am I?" (intrapersonal), and "Who do I relate to?" (interpersonal) (Baxter Magolda, 2009). Based on the massive narratives collected from a longitudinal study in over 25 years' span, the trajectory of selfauthorship development was framed by Baxter Magolda (2009) as a journey that traveled from fully relying on the external resources to the establishment of an inner voice. Later, as part of the research output of the Wabash National Study of Liberal Arts Education (Baxter Magolda \& King, 2007), a four-stage model of self-authorship development was proposed, in an order of solely external, entering the crossroads, leaving the cross-roads, and solely internal. The existing research on self-authorship was mainly conducted among the U.S. university populations (e.g. Creamer \& Laughlin, 2005; Wawrzynski \& Pizzolato, 2006). 
More recently, researchers started to explore self-authorship among Chinese students (see a detailed review in Xie, 2018). Despite the increasing research interest, there is still a lack of knowledge in the self-authorship development among Chinese university students. Furthermore, insufficient efforts were made in utilizing quantitative measures to understand either the relationships among dimensions of self-authorship or on the subtle nuances on different phases in the development of self-authorship (Creamer et al., 2010). Acknowledging the above research gaps, the current study was designed to validate a quantitative measure, the Self-authorship Section of the Career Decision Making Survey (SA-CDMS; Creamer et al., 2010) among Chinese university students. It is hypothesized that this measure would be suitable for assessing Chinese university students' selfauthorship, however, the reliability and validity of this measure might be affected when it was applied in different cultural contexts.

\section{Methods}

\subsection{Participants}

Invited from three public comprehensive universities in the People's Republic of China, 263 participants (210 males, 51 females) whose ages ranged from 19 to 23 years joined Stage One, and 663 participants (513 males, 136 females) aged from 16 to 22 years joined Stage Two. As the data was collected in part of a research project designed to explore the university developmental outcomes among Chinese university students in science, technology, engineering, and mathematics majors, most participants were male students. The participation was entirely voluntary based.

\subsection{Measurement}

The quantitative measure adopted by this study first appeared in the section called 'Diverse Viewpoints and Decision Making' of the Career Decision Making Survey (CDMS) employed by the Woman and Information Technology (WIT) team to explore female students' career choices toward information technology. The original self-authorship section of CDMS consisted of 28 items in 4-point Likert-type scales. Based on Baxter Magolda's (2009) suggestion and results from the preliminary validation study (Yue, Creamer, \& Wolfe, 2009), an 18-item SA-CDMS was derived (Creamer et al., 2010) to assess five prompts of career decision making and two prompts of epistemological development. Each item measured one of the first three phases of development in selfauthorship (i.e. external formula, cross-roads, and early stage of self-authorship), as well as one of the three theoretical dimensions (i.e. epistemological, intrapersonal, and interpersonal). To date, only one study (Zhang \& Cen, 2017) administrated SA-CDMS to Chinese university students. The reliability and validity of this quantitative measure in the 
Chinese higher education context remain under-explored. The original English-version of SA-CDMS was derived from Creamer et al.'s (2010) journal article. Professional advice was sought in the process of translating SA-CDMS from English to Chinese, with the translation-back-translation procedure adopted.

\subsection{Procedures}

Prior to the data collection, this study had obtained research ethics approval from the Human Research Ethics Committee of the author's affiliation. In both stages of this study, paper-and-pen questionnaires were distributed to the volunteer participants during the class breaks. The participants firstly read through the descriptions of the research aims and procedures, then gave written consent. After completion, the questionnaires were returned to the researcher and be sealed in storing envelopes. Two statistical software, IBM SPSS (v.22) and IBM AMOS (v.24) were employed to analyze the data.

\section{Results}

\subsection{Stage One}

Stage One aimed at preliminarily examine the psychometric properties of the translated SACDMS. Internal consistency tests and exploratory factor analysis were employed to access the reliability and validity of this measure, respectively.

\subsubsection{Stage One- internal consistency test}

Internal consistency of each dimension, as well as each phase of self-authorship, was calculated separately. Cronbach's alpha coefficients for the three phases of self-authorship were 0.65 (external formula), 0.64 (cross-roads), and 0.27 (early stage of self-authorship); for the three theoretical dimensions were 0.72 (interpersonal), 0.10 (intrapersonal), and 0.71 (epistemological). It is worthy noted that the reliabilities of the early stage of selfauthorship and the intrapersonal dimension were severely affected by Item 6. Also shown in the item-total statistics table from the consistency tests output, the Cronbach' alpha coefficients could be improved to 0.66 (for the early stage of self-authorship phase) and 0.5 (for the intrapersonal dimension) respectively, if Item 6 was deleted from the subscales.

\subsubsection{Stage One- exploratory factor analysis}

Exploratory factor analysis with principal component analysis and varimax rotation of the 18 items in SA-CDMS yielded four factors (eigenvalues being 5.09, 1.22, 1.12, and 1.05, respectively), explaining $47.14 \%$ of the variances in the data. Statistics of the KaiserMayer-Olkin and Bartlett's Test were $\mathrm{KMO}=0.89$, Chi-Square $\chi^{2}=975.83, \mathrm{df}=153$, and $p$ $<.000$, indicating that the current data was adequate for the factor analysis. The rotated 
pattern matrix showed that Item 6 loaded solely on Factor 4. With factor loadings of less than 0.35 surpassed, four items (Item 11, 12, 13, and 15) still cross-loaded on two factors. Except for these obviously problematic items, the overall loading patterns also failed to support neither the three-dimension nor the three-phase structure as suggested by the selfauthorship model.

\subsubsection{Implications for the Stage Two}

Although the item-level factor analysis of the original 18-item SA-CDMS failed to generate factors as expected while two subscales performed poorly in the internal consistency tests, possible modifications could be identified from the results of Stage One. First, Item 6 was considered as problematic due to the severe side effects it caused on the reliability of the subscales. In addition, Item 6 loaded on Factor 4 by itself with a factor loading of 0.902 . Theoretically, this item should load on the epistemological dimension, as well as the crossroads phase (see Table 1). Second, wording and sentence structure of some items need to be modified. For example, some items (i.e. Item 3,7,8,12) contained the concept of "career counselor" which was not familiar to the university students in China. Third, items were missed from the intrapersonal dimensions on the cross-roads and early stage of selfauthorship phases under the prompt of making educational choices (i.e. choosing major for one's tertiary education) in the original SA-CDMS. Two additional items were designed based on Creamer et al.'s (2010) framework and the existing literature. Item distribution of the modified SA-CDMS was shown in a 3-dimension-by-3-phase chart (See Table 1). Fourth, the layout needed to be adjusted to make the SA-CDMS brief and easy to read. One solution would be clustering items under the same prompt into one sub-section, with each subsection started with the description sentence of the prompt.

Table 1. Item distributions in the $3 \times 3$ matrix of self-authorship framework.

\begin{tabular}{llll}
\hline & Interpersonal & Intrapersonal & Epistemological \\
\hline External Formula & Item 1, 17 & Item 2, 8 & Item 4, 13 \\
Cross-roads & Item 10, 19 & Item 9, 14* & Item 3, 6 \\
Early Stage of Self-authorship & Item 5, 12 & Item 18, 20* & Item 7, 11,15, 16 \\
\hline
\end{tabular}

Note: * Newly added items to the intrapersonal dimension.

\subsection{Stage Two}

Based on the results from Stage One, one problematic item (i.e. Item 6) was dropped from the original SA-CDMS while two new items were added to the intrapersonal dimension. At the same time, wording, sentence structure, and the layout of the inventory were adjusted. To further examine the psychometric properties of the modified 19-item SA-CDMS, Stage 
Two of the current study conducted internal consistency tests and confirmatory factor analysis. In addition, the correlations among demographics (i.e. age, gender, father's educational attainment, and mother's educational attainment), three phases, and three dimensions of the self-authorship framework were examined, aiming at offering additional information for the theoretical propositions of the self-authorship model.

\subsubsection{Stage Two- internal consistency test}

Internal consistency test yielded moderate reliability of the modified SA-CDMS, with Cronbach's alpha coefficients of 0.61 (external formula phase), 0.64 (cross-roads phase), 0.7 (early stage of self-authorship phase), 0.6 (interpersonal dimension), 0.62 (intrapersonal dimension), and 0.6 (epistemological dimension).

\subsubsection{Stage Two- confirmatory factor analysis}

In the beginning, the model fit indices from the confirmatory factor analysis indicated an inadequate fit between the 19-item three-developmental-phase SA-CDMS model and the observed data. The modification indices also revealed high covariances between the errors of Item 12 and Item 16 (M.I.= 104.68), Item 8 and Item 17 (M.I.= 87.92), Item 4 and Item 17 (M.I.= 48.03), as well as Item 4 and Item 8 (M.I.=42.279). Besides, factor loadings of Item 4, Item 15, and Item 17 were 0.29, 0.29, and 0.25, respectively, which were lower than the cut-off value of 0.32 (Tabachnick, Fidell, \& Ullman, 2007). Item 8 and Item 17 also had side effects on the reliability of SA-CDMS. Bi-directional arrows were added in between the highly correlated errors. Computation after the modification produced good model fit indices: Chi-square $\chi^{2}(\mathrm{df}=145)=383, p<.000, \mathrm{RMSEA}=.076, \mathrm{SRMR}=.05$, and $\mathrm{CFI}=.903$ (Hu \& Bentler, 1999).

\subsubsection{Correlations among demographics, dimensions, and phases of self-authorship}

As shown in Table 2, there was statistically significantly negative correlations found between age and the cross-roads phase $(r=-0.095, p<0.05)$, when statistically significantly positive correlations were found between gender and cross-roads phase $(r=0.087, p<0.05)$, as well as parents' educational attainment and epistemological dimension $\left(r_{\text {father_edu-epis }}=0.13\right.$, $\left.p<0.01 ; r_{\text {mother_edu-epis }}=0.119, p<0.05\right)$. Also shown in Table 2 , even when the potential confounding effects of demographics had been partialized out, moderate to strong positive correlations were still found among the three developmental phases and three dimensions of self-authorship. Regarded the three pairs of correlations among the three phases in the development of self-authorship, the weakest correlation was between the external formula phase and the cross-roads phase $(r=0.459, p<0.001)$ while the strongest correlation was between the cross-roads phase and the early stage of self-authorship phase $(r=0.595, p<$ 0.001). Regarded the correlations among the three theoretical dimensions of self-authorship, the interpersonal dimension was more strongly related to the epistemological dimension $(r$ 
$=0.657, p<0.001)$, than that of intrapersonal dimension to epistemological dimension $(r=$ $0.628, p<0.001)$.

Table 2. Correlations between demographics, dimensions, and phases of self-authorship

\begin{tabular}{|c|c|c|c|c|c|c|c|c|c|}
\hline Measure & 2 & 3 & 4 & 5 & 6 & 7 & 8 & 9 & 10 \\
\hline 1.Age & $-.078^{*}$ & .028 & .064 & -.002 & $-.095 *$ & -.007 & -.026 & -.052 & -.018 \\
\hline 2.Gender & - & .039 & .035 & .074 & $.087 *$ & .015 & .05 & .068 & .051 \\
\hline 3.Father_edu & & - & $.71 * *$ & .076 & .072 & .074 & .067 & .031 & $.13 * *$ \\
\hline 4.Mother_edu & & & - & .069 & .062 & .071 & .078 & .011 & $.119 *$ \\
\hline \multirow{2}{*}{ 5.External formula } & & & & - & .459 & $.528 *$ & .74 & .664 & .677 \\
\hline & & & & & $* * *$ & $* *$ & $* * *$ & $* * *$ & $* * *$ \\
\hline \multirow[t]{2}{*}{ 6.Cross-roads } & & & & & - & $.595^{*}$ & .643 & .771 & .685 \\
\hline & & & & & & $* *$ & $* * *$ & $* * *$ & $* * *$ \\
\hline 7.Early-stage of self- & & & & & & - & .795 & .739 & .803 \\
\hline authorship & & & & & & & $* * *$ & $* * *$ & $* * *$ \\
\hline \multirow[t]{2}{*}{ 8.Interpersonal } & & & & & & & - & .68 & .657 \\
\hline & & & & & & & & $* * *$ & $* * * *$ \\
\hline \multirow[t]{2}{*}{ 9.Intrapersonal } & & & & & & & & - & .628 \\
\hline & & & & & & & & & $* * *$ \\
\hline 10.Epistemological & & & & & & & & & - \\
\hline
\end{tabular}

Notes: ***. Correlation is significant at the 0.001 level (2-tailed); **. Correlation is significant at the 0.01 level (2-tailed); *. Correlation is significant at the 0.05 level (2-tailed).

\section{Conclusion}

The current study was designed in exploratory nature with restrictions of at least three limitations. First, participants of this study were not selected by random sampling, instead, volunteers were recruited from a convenient sample. Second, given the complex structure of self-authorship (i.e. multidimensional and multiphase), it is reasonable to doubt that the self-reported questionnaire data collected by the current study might not be able to reflect all the details of students' orientations toward self-authorship. Third, except for the demographic factors considered by the current research, there still are other potentially influential factors. For example, the influence of the psychosocial aspect of the learning environment (e.g. teacher-student interaction, peer morale, etc.) was not included.

In summary, the current study provided empirical evidence in adapting the SA-CDMS to the Chinese higher educational context. The current study contributed to the theory on selfauthorship that (1) The moderately positive correlations among the dimensions of self- 
authorship indicated that the dimensions of self-authorship were intertwined with each other; (2) The strengths of correlations among the three dimensions also indicated that individual's concept of knowledge (epistemological) was more closely related to his or her perspectives on others (interpersonal) than the views of one's own role in the meaningmaking process (intrapersonal). (3) Regarded the correlations among the three phases of self-authorship development, the results supported Meszaros, Creamer, and Lee's (2007) finding that individuals need to take a big leap from fully dependent on others to start noticing one's own voices. Finally, the practical implication can be offered to stakeholders in Chinese higher educational institutions that it is possible to use SA-CDMS as an assessment tool for the training courses or educational interventions that aim at promoting self-authorship development.

\section{References}

Magolda, M. B. B. (2009). The activity of meaning making: A holistic perspective on college student development. Journal of College Student Development, 50(6), 621-639. doi:http://dx.doi.org.eproxy.lib.hku.hk/10.1353/csd.0.0106

Magolda, M. B. B., \& King, P. M. (2007). Interview strategies for assessing selfauthorship: Constructing conversations to assess meaning making. Journal of College Student Development, 48(5), 491-508. doi:http://.doi.org/10.1353/csd.2007.0055

Creamer, E. G., Magolda, M. B., \& Yue, J. (2010). Preliminary evidence of the reliability and validity of a quantitative measure of self-authorship. Journal of College Student Development, 51(5), 550-562. doi:http://dx.doi.org/10.1353/csd.2010.0010

Creamer, E. G., \& Laughlin, A. (2005). Self-authorship and women's career decision making. Journal of College Student Development, 46(1), 13-27. doi:http://dx.doi.org.eproxy.lib.hku.hk/10.1353/csd.2005.0002

Hu, L., \& Bentler, P. M. (1999). Cutoff criteria for fit indexes in covariance structure analysis: Conventional criteria versus new alternatives. Structural Equation Modeling, 6(1), 1-55. doi:http://dx.doi.org.eproxy.lib.hku.hk/10.1080/107055199095118

Kegan, R. (1994). In over our heads: The mental demands of modern life. Cambridge,

Meszaros, P. S., Creamer, E., \& Lee, S. (2009). Understanding the role of parental support for IT career decision making using the theory of self-authorship. International Journal of Consumer Studies, 33(4), 392-395. doi:http://dx.doi.org.eproxy.lib.hku.hk/10.1111/j.1470-6431.2009.00790.x

Perez, R. J. (2017). Enhancing, inhibiting, and maintaining voice: An examination of student affairs graduate students' self-authorship journeys. Journal of College Student Development, 58(6), 833-852. doi:http://dx.doi.org/10.1353/csd.2017.006

Piaget, J. (1950). Explanation in sociology. Sociological studies, 30, 96.

Pizzolato, J. E. (2007). Assessing self-authorship. New Directions for Teaching \& Learning, 2007(109), 31-42. doi:https://doi-org.eproxy.lib.hku.hk/10.1002/tl.263 
Tabachnick, B. G., Fidell, L. S., \& Ullman, J. B. (2007). Using multivariate statistics (Vol. 5). Boston, MA: Pearson.

Yue, J., Creamer, E. G., \& Wolfe, E. (2009, April). Measurement of self-authorship: A validity study using multidimensional random coefficients multinomial logit model. In American Educational Research Association National Conference, San Diego, CA.

解啟健,. 自我主導力理論在高等教育領域的應用與發展 [J]. 江蘇高教,2017,(7).

張宇晴,岑逾豪, 大學生自我主導發展水平及影響因素探究——以職業選擇為場域 $[\mathrm{J}]$. 吉林省教育學院學報,2017,(3). 